\title{
Hypothesizing Darkness Induced Alcohol Intake Linked to Dopaminergic Regulation of Brain Function
}

\author{
Kenneth Blum 1,3-8, Marlene Oscar-Berman², Rajendra D. Badgaiyan', Eric R. Braverman1,6, \\ Mark S. Gold1 \\ ${ }^{1}$ Department of Psychiatry \& McKnight Brain Institute, College of Medicine, University of Florida, Gainesville, \\ USA \\ ${ }^{2}$ Department of Psychiatry and Neurology, School of Medicine and Veterans Administration System, Boston \\ University, Boston, USA \\ ${ }^{3}$ Department of Addiction Research \& Therapy, Malibu Beach Recovery Center, Malibu Beach, USA \\ ${ }^{4}$ Department of Psychiatry \& Human Integrated Services Unit, College of Medicine, University of Vermont \\ Center for Clinical \& Translational Science, Burlington, USA \\ ${ }^{5}$ Department of Nutrigenomics, BioClarity, Inc., La Jolla, USA \\ ${ }^{6}$ Department of Clinical Neurology, Path Foundation, New York, USA \\ ${ }^{7}$ Department of Personalized Medicine, IGENE, LLC., Austin, USA \\ ${ }^{8}$ Dominion Diagnostics, LLC., North Kingstown, USA \\ ${ }^{9}$ Department of Psychiatry and Laboratory of Neuroimaging and Molecular Imaging, School of Medicine and \\ Biomedical Sciences, University at Buffalo Buffalo, New York, USA \\ Email: drd2gene@gmail.com, msgold@ufl.edu, osca@bu.edu, pathmedical@aol.com, rajedra@wjh.harvard.edu
}

Received 23 January 2014; revised 22 February 2014; accepted 21 March 2014

Copyright (C) 2014 by authors and Scientific Research Publishing Inc.

This work is licensed under the Creative Commons Attribution International License (CC BY).

http://creativecommons.org/licenses/by/4.0/

(c) (i) Open Access

\begin{abstract}
Understanding the role of neurotransmission in the prefrontal cortex and mesolimbic brain regions has become the subject of intensive neuroscience research worldwide. In the 1970s, our group provided evidences that rats exposed to darkness significantly augmented their alcohol intake. At that time, we proposed that melatonin was the culprit. At around the same time, our laboratory, amongst a few others, proposed that dopamine-adducts with acetaldehyde to induce alcohol intake both in rodents and in humans. While the work in these areas has declined considerably over the years, more recent scientifically sound studies continue to show the importance of these earlier controversial ideas involving alcohol abuse and alcoholism. A review of the literature has provided impetus to systematically access the newer genetic and molecular neurobiological findings relevant to the physiological and psychological motives for high alcohol consumption in animals and humans alike. Thus, we hypothesize that darkness-induced alcohol intake is linked
\end{abstract}


not only to serotonergic-melatonin mechanisms, but also to dopaminergic regulation of brain mesolimbic pathways involving neuronal expression switching in response to long photoperiods affecting gene expression.

\section{Keywords}

\section{Photoperiod; Alcohol Intake; Dopamine; Reward Pathway; Serotonin and Melatonin; Nocturnal}

\section{Introduction}

In the mid 1960s, very little was known about brain function and neurotransmitter activity. At that time, even less was known about the interaction of neurochemicals and alcohol effects. In fact, one of the first relevant studies was executed by Myers and Veale in 1968, showing that preference for ethanol (alcohol) was significantly attenuated or totally eliminated in rats given p-chlorophenylalanine (PCA), a tryptophan hydroxylase inhibitor that selectively depletes brain serotonin content (Myers \& Veale, 1968). The depleting action of PCA was more powerful than alpha-methyl-p-tyrosine, a tyrosine hydroxylase inhibitor that depletes brain catecholamines. This is not surprising considering anti-anxiety properties of alcohol in humans and in nonhuman animal models (Steiner, 1958). It is well-known that PCA induces “conflict” behavior in rats (Robichaud \& Sledge, 1969), and this effect can be attenuated by the administration of 5-hydroxy-tryptophane (Geller \& Blum, 1970). This suggests that PCA promotes anxiety and serotonin is an anti-anxiety brain substance.

It is well-known that levels of brain serotonin, especially in the pineal gland, are lowest during a dark phase, because of its conversion to melatonin via adenylate cyclase induced stimulation of N-Acetyltransferase activity which increase three-fold at night (Coon et al., 2012; Namboodiri, Sugden, Klein, Tamarkin, \& Mefford, 1985; Raiewski, Elliott, Evans, Glickman, \& Gorman, 2012). Specifically, pineal melatonin levels are low during the day, increase five to ten-fold at night, decrease during a light pulse at night, and rapidly increase to night levels following the light-dark transition (Namboodiri, Sugden, Klein, Tamarkin, \& Mefford, 1985).

In the early 1970s, Blum's group provided evidence for darkness-induced enhancement of ethanol drinking in rodents. The first report showed that rats placed in a dark closet drank more alcohol than those housed in the light (Geller, 1971). Blum theorized that the increased drinking was due to an increase in pineal melatonin, and subsequent experiments revealed this to be accurate, since injections of melatonin in rats exposed under "normal” photoperiods (nine hours of darkness during a 24-hour day) also displayed augmented ethanol intake (Geller, 1971; Sinclair, 1972).

Along these lines, a number of subsequent experiments revealed that enhanced ethanol consumption by not only rats, but also by Syrian hamsters indeed involved the pineal gland (Blum, Merritt, Reiter, \& Wallace, 1973; Reiter, Blum, Wallace, \& Merritt, 1973, 1974). Firstly, it was shown that a lesion to the superior cervical ganglion innervation to the pineal gland blocked darkness-induced ethanol drinking in Syrian hamsters (Reiter et al., 1974). Secondly, augmented ethanol drinking occurred in congenitally blind male rats never exposed to ethanol prior to experimental induction (Reiter et al., 1973). Finally, Blum et al. (1973) concluded that melatonin-induced drinking, due to a photoperiod, involved modifications in serotonin synthesis as a function of the photoperiod (Blum et al., 1973). While this was one theory concerning the neurochemical mechanism(s) of ethanol consumption, other earlier experiments suggested the role of condensation products, known as isoquinolines.

The most notable was the work of Davis and Walsh, who proposed that tetrahydropapaverline, a benzyltetrahydroisoquinoline alkaloid derivative of the biogenic amine, dopamine, and acetaldehyde, a product of alcohol, condenses and can induce ethanol intake in rodents (Davis \& Walsh, 1970). Moreover, they suggested that alcohol and opiate addiction might have common neurochemical mechanisms. At the same time, others reported on biogenic amines (e.g., norepinephrine) (Cohen \& Collins, 1970) and indolamines (serotonin) (Myers, 1989) aldehyde condensation products and their role in alcoholism. While these ideas met with great controversy, Blum's group provided clear evidence that ethanol intake increased the metabolite of salsolinol in rat brain (Hamilton, Blum, \& Hirst, 1978); salsolinol induced augmented alcohol intake; salsolinol acted like an opiate (Blum, DeLallo, Briggs, \& Hamilton, 1982); and salsolinol induced alcohol withdrawal tremors (Blum, 1988; Blum, Hamilton, Meyer, Hirst, \& Marshall, 1977). 
In summary, abnormal intake of alcohol is related to opioid receptors in the brain, and this is based on early thinking. By comparison, the attenuation of alcohol drinking was associated with opioid receptor antagonists (Marshall, Hirst, \& Blum, 1977), binding of a tetrahydroisoquinolin (THIQ) to opiate receptors in the brain (Blum, Eubanks, Wallace, Schwertner, \& Morgan, 1976; Myers, 1989), and marked differences in enkephalin values in animals genetically predisposed to the ingestion of alcohol (Blum, Elston, DeLallo, Briggs, \& Wallace, 1983). Finally, Myers (Myers, 1989) proposed that the dopaminergic reward pathways that traverse the mesolimbic-forebrain systems of the brain constitute an "integrative anatomical substrate for the adduct-opioid cascade of neuronal events which promote and sustain the aberrant drinking of alcohol”.

\section{Relationship to Alcohol Use and Abuse}

To our knowledge, other than work related to alcohol intoxication and withdrawal per se, little was known with regard to the role of dopaminergic function and vulnerability of aberrant ethanol consumption in humans (Blum, Eubanks, Wallace, \& Schwertner, 1976). In fact, while dopaminergic mechanisms have been espoused for the role of dopamine and cocaine addiction (Dackis \& Gold, 1985), a quick search in PUBMED revealed that the first real evidence for involvement of dopamine and alcoholism, especially genetic vulnerability, was provided by Blum et al. (Blum et al., 1990). Interestingly, the concepts related to dopamine adducts with alcohol lost favor in the scientific community in the mid 1980s until the early 2000s. However, there has been a new surge of studies that shows important pharmacological effects of at least salsolinol. To reiterate, ethanol excites dopamine neurons in the posterior ventral tegmental area (pVTA). This effect is responsible for ethanol's motivational properties and may contribute to alcoholism.

Very recent studies by Melis et al. (Melis, Carboni, Caboni, \& Acquas, 2013) demonstrated that salsolinol, when administered in pVTA, excites pVTA dopamine cells, elicits dopamine transmission in nucleus accumbens, and sustains its self-administration in pVTA. This finding is similar to morphine, indicating opioid like effects of salsolinol as noted earlier (Hamilton, Hirst, \& Blum, 1979).

Review of the old and newer data clearly reveals that within the well-established brain reward circuitry, alcohol metabolites (e.g., dopamine and acetaldehyde) are involved in alcohol induced effects as indicted herein: 1) biologically active metabolites of alcohol can directly or indirectly increase the activity of VTA dopamine neurons, 2) alcohol and alcohol metabolites are reinforcing within the mesolimbic dopamine system, 3) inhibiting the alcohol metabolic pathway inhibits the biological consequences of alcohol exposure, 4) alcohol consumption can be reduced by inhibiting/attenuating the alcohol metabolic pathway in the mesolimbic dopamine system, 5) alcohol metabolites can alter neurochemical levels within the mesolimbic dopamine system, and 6) alcohol interacts with alcohol metabolites to enhance the actions of both compounds (Deehan, Hauser, Wilden, Truitt, \& Rodd, 2013). Accordingly, there is a positive relationship between alcohol and alcohol metabolites in regulating the alcohol intake, and these biological consequences lead to an escalation to alcoholism (Deehan, Brodie, \& Rodd, 2013). Furthermore, fortification of these results has adequately shown that salsolinol can induce dopamine release in the mesolimbic brain region, supporting earlier indications (Hipolito, Sanchez-Catalan, Granero, \& Polache, 2009; Melchior, Simpson, \& Myers, 1978). Finally, T-K Li’s group (Rodd et al., 2008) showed that infusions of salsolinol produced reinforcing effects in the pVTA of Wistar rats, and these actions were mediated by activation of DA neurons (D2/D3 receptors) and local 5-HT3 receptors. There is also evidence that salsolinol's reinforcing effects under stress involve endorphinergic mechanisms (Matsuzawa, Suzuki, \& Misawa, 2000).

The importance of these findings involving alcohol metabolites underscores the potential role of reward circuitry signaling involving serotonergic, endorphinergic, gabaergic, and dopaminergic functionality in alcohol intake as well as reward deficiency syndrome (Blum, Gardner, Oscar-Berman, \& Gold, 2012). We crafted this commentary relying on earlier studies suggesting that potential vulnerability to alcoholism may reside in not only the reinforcing properties of alcohol metabolites as indicated with salsolinol, but environmental alterations of light/dark cycles or photoperiods. Our understanding in the 1970s-1980s concerning alcohol vulnerability was very limited due to a paucity of gene related studies. In addition, during this earlier time period, little was known about the role of neurotransmitters in photoperiods. Thus, the impetus for this hypothesis is based in part on newer findings that will contribute to our knowledge on darkness-induced alcohol intake. Importantly, Yaegashi et al. investigated the relationship between salsolinol induced prolactin (PRL) release and photoperiod in goats. They found that the releasing effect of PRL by salsolinol was enhanced during long (dark) photoperiods. It suggests that this effect could be mediated by enhanced dopamine release (Yaegashi et al., 2012). 
Since the 1970s, there has been a number of important articles on the brain reward cascade (Blum et al., 2000) that shed light on the interaction of serotonin, melatonin, enkephalins, acetylcholine, and dopamine on darkness-induced alcohol intake. Recently, Crespi (Crespi, 2012) further supported the role of melatonin in ethanol consumption in $\mathrm{P}$ (alcohol-preferring) rats by blocking spontaneous consumption of ethanol with a melatonin antagonist GR128107. It also has been shown that $10 \%$ chronic ethanol significantly reduces pineal peak melatonin synthesis by $70 \%$ partly, due to a phase delay in arylalkylamine $\mathrm{N}$-acetyltransferase gene expression (Peres et al., 2011).

Ethanol preferring C57Bl/6J mice "drink in the dark" (DID) until intoxicated (model for binge drinking), and this effect involves nicotinic acetylcholine type brain receptors (nACHRs). It was found that nACHRs are indeed involved in ethanol intake in the DID paradigm. Specifically, the nicotinic acetylcholine receptor antagonist mecamylamine not only reduced ethanol consumption of these mice in the dark, it also blocked ethanol activation of dopaminergic neurons (Hendrickson, Zhao-Shea, \& Tapper, 2009). This work is in agreement with earlier experiments by Ericson et al. showing that ethanol enhances accumbal dopamine levels via indirect activation of VTA nACHRs (Ericson, Molander, Lof, Engel, \& Soderpalm, 2003). It is noteworthy that melatonin also regulates an endogenous opioid system (EOS)-circadian rhythm. The work by Miguel Asai et al. (2007) suggests that during the dark phase, melatonin enhances the EOS by increased tissue content of enkephalins in both hypothalamus and hippocampus of the rat brain, and in constant light the absence of melatonin leads to a decrease of tissue enkephalins (Miguel Asai et al., 2007). This may have some relevance in terms of understanding the role of enkephalins inhibitory effect on GABA neurons leading to altered dopamine release during photoperiods.

A very recent study by Dulcis et al. (2013) suggested that photoperiod-induced neurotransmitter switching could regulate brain function and subsequent adult behavior in rats (Dulcis, Jamshidi, Leutgeb, \& Spitzer, 2013). They found that populations of interneurons in the adult rat hypothalamus switched between dopamine and somatostatin expression in response to exposure to short- and long-day photoperiods. Interestingly, changes in postsynaptic dopamine receptor expression matched changes in presynaptic dopamine, whereas somatostatin receptor expression remained constant. Moreover, pharmacological blockade or ablation of these dopaminergic neurons led to anxious and depressed behavior, "phenocopying" performance after exposure to the long-day photoperiod. Thus, during darkness, dopaminergic expression is reduced and this could be responsible in part for our previous findings involving darkness-induced ethanol intake (Blum et al., 1973; Reiter et al., 1973, 1974). This notion is fortified by their additional finding that exposure of the short-day photoperiod induced the synthesis of new dopaminergic neurons that "rescued" the resultant behaviors observed during the dark phase (Dulcis et al., 2013).

\section{Conclusion}

In summary, we are encouraged that following many years of research (Bruijnzeel \& Gold, 2005; Dackis et al., 1984; Ebadi, Weiss, \& Costa, 1970), the neurochemical mechanisms involved in the now established darkness-induced drinking paradigm has been further advanced (Sleipness, Jansen, Schenk, \& Sorg, 2008). Based on the findings espoused in this hypothesis, the newer concepts of the role of both dopamine adducts (Hamilton, Blum, \& Hirst, 1980; Sallstrom Baum, Hill, Kiianmaa, \& Rommelspacher, 1999) and darkness-induced dopamine switching provides a fruitful avenue of investigation (El Halawani, Kang, Leclerc, Kosonsiriluk, \& Chaiseha, 2009). While many future studies certainly will clarify the role of gene polymorphisms (Blum et al., 1990; Wang, Simen, Arias, Lu, \& Zhang, 2013) including epigenetics and related behavioral endophenotypes, the concept that all roads lead to dopamine certainly continues to be an important therapeutic target ultimately leading to prevention of relapse and potential abolition of alcoholism (Balldin, Berggren, Berglund, \& Fahlke, 2013; Blum, Futterman, \& Pascarosa, 1977; Dahlgren et al., 2011; Self \& Nestler, 1998).

\section{Acknowledgements}

We appreciate the expert edits of Margaret A. Madigan, as well as the PATH staff including Florian Kreuk, Mona Li, Kristina Dushhaj, and Courtney Trudesdell. The preparation and review of the manuscript was supported in part by funds from the National Institutes of Health, NIAAA (R01-AA07112 and K05-AA00219) and the Medical Research Service of the US Department of Veterans Affairs (Marlene Oscar-Berman). Dr. Kenneth Blum and Eric R. Braverman are the recipients of a grant from Life Extension Foundation, Ft. Lauderdale, Flor- 
ida. Dr. Badgaiyan is supported by the National Institutes of Health grants 1R01NS073884 and 1R21MH073624, and VA Merit Review Awards CX000479 and CX000780.

\section{References}

Balldin, J., Berggren, U., Berglund, K., \& Fahlke, C. (2013). Why Some People Relapse in Alcohol Dependence. There Is a Relation to a Specific Gene Variant in the Dopamine System and to Psychology. Lakartidningen, 110, 21-23.

Blum, K. (1988). Narcotic Antagonism of Seizures Induced by a Dopamine-Derived Tetrahydroisoquinoline Alkaloid. Experientia, 44, 751-753. http://dx.doi.org/10.1007/BF01959150

Blum, K., Braverman, E. R., Holder, J. M., Lubar, J. F., Monastra, V. J., Miller, D., \& Comings, D. E. (2000) Reward Deficiency Syndrome: A Biogenetic Model for the Diagnosis and Treatment of Impulsive, Addictive, and Compulsive Behaviors. Journal of Psychoactive Drugs, Suppl 32, 1-112. http://dx.doi.org/10.1080/02791072.2000.10736099

Blum, K., DeLallo, L., Briggs, A. H., \& Hamilton, M. G. (1982). Opioid Responses of Isoquinoline Alkaloids (TIQs). Progress in Clinical and Biological Research, 90, 387-398.

Blum, K., Elston, S. F., DeLallo, L., Briggs, A. H., \& Wallace, J. E. (1983). Ethanol Acceptance as a Function of Genotype Amounts of Brain [Met] Enkephalin. Proceedings of the National Academy of Sciences of the United States of America, 80, 6510-6512. http://dx.doi.org/10.1073/pnas.80.21.6510

Blum, K., Eubanks, J. D., Wallace, J. E., Schwertner, H., \& Morgan, W. W. (1976). Possible Role of Tetrahydroisoquinoline Alkaloids in Postalcohol Intoxication States. Annals of the New York Academy of Sciences, 273, 234-246. http://dx.doi.org/10.1111/j.1749-6632.1976.tb52887.x

Blum, K., Eubanks, J. D., Wallace, J. E., \& Schwertner, H. A. (1976). Suppression of Ethanol Withdrawal by Dopamine. Experientia, 32, 493-495. http://dx.doi.org/10.1007/BF01920816

Blum, K., Futterman, S. L., \& Pascarosa, P. (1977). Peyote, a Potential Ethnopharmacologic Agent for Alcoholism and Other Drug Dependencies: Possible Biochemical Rationale. Clinical Toxicology, 11, 459-472. http://dx.doi.org/10.3109/15563657708988210

Blum, K., Gardner, E., Oscar-Berman, M., \& Gold, M. (2012). "Liking” and "Wanting” Linked to Reward Deficiency Syndrome (RDS): Hypothesizing Differential Responsivity in Brain Reward Circuitry. Current Pharmaceutical Design, 18, 113-118. http://dx.doi.org/10.2174/138161212798919110

Blum, K., Hamilton, M. G., Meyer, E. K., Hirst, M., \& Marshall, A. (1977). Isoquinoline Alkaloids as Possible Regulators of Alcohol Addiction. Lancet, 1, 799-800. http://dx.doi.org/10.1016/S0140-6736(77)92981-6

Blum, K., Merritt, J. H., Reiter, R. J., \& Wallace, J. E. (1973). A Possible Relationship between the Pineal Gland and Ethanol Preference in the Rat. Current Therapeutic Research, Clinical and Experimental, 15, 25-30.

Blum, K., Noble, E. P., Sheridan, P. J., Montgomery, A., Ritchie, T., Jagadeeswaran, P., \& Cohn, J. B. (1990). Allelic Association of Human Dopamine D2 Receptor Gene in Alcoholism. JAMA: The Journal of the American Medical Association, 263, 2055-2060. http://dx.doi.org/10.1001/jama.1990.03440150063027

Bruijnzeel, A. W., \& Gold, M. S. (2005). The Role of Corticotropin-Releasing Factor-Like Peptides in Cannabis, Nicotine, and Alcohol Dependence. Brain Research. Brain Research Reviews, 49, 505-528. http://dx.doi.org/10.1016/j.brainresrev.2005.01.007

Cohen, G., \& Collins, M. (1970). Alkaloids from Catecholamines in Adrenal Tissue: Possible Role in Alcoholism. Science, 167, 1749-1751. http://dx.doi.org/10.1126/science.167.3926.1749

Coon, S. L., Munson, P. J., Cherukuri, P. F., Sugden, D., Rath, M. F., Moller, M., \& Klein, D. C. (2012). Circadian Changes in Long Noncoding RNAs in the Pineal Gland. Proceedings of the National Academy of Sciences of the United States of America, 109, 13319-13324. http://dx.doi.org/10.1073/pnas.1207748109

Crespi, F. (2012). Influence of Melatonin or Its Antagonism on Alcohol Consumption in Ethanol Drinking Rats: A Behavioral and in Vivo Voltammetric Study. Brain research, 1452, 39-46. http://dx.doi.org/10.1016/j.brainres.2011.10.050

Dackis, C. A., Bailey, J., Pottash, A. L., Stuckey, R. F., Extein, I. L., \& Gold, M. S. (1984). Specificity of the DST and the TRH Test for Major Depression in Alcoholics. The American Journal of Psychiatry, 141, 680-683.

Dackis, C. A., \& Gold, M. S. (1985). New Concepts in Cocaine Addiction: The Dopamine Depletion Hypothesis. Neuroscience and Biobehavioral Reviews, 9, 469-477. http://dx.doi.org/10.1016/0149-7634(85)90022-3

Dahlgren, A., Wargelius, H. L., Berglund, K. J., Fahlke, C., Blennow, K., Zetterberg, H., \& Balldin, J. (2011). Do AlcoholDependent Individuals with DRD2 A1 Allele Have an Increased Risk of Relapse? A Pilot Study. Alcohol and alcoholism, 46, 509-513. http://dx.doi.org/10.1093/alcalc/agr045

Davis, V. E., \& Walsh, M. J. (1970). Alcohol, Amines, and Alkaloids: A Possible Biochemical Basis for Alcohol Addiction. Science, 167, 1005-1007. http://dx.doi.org/10.1126/science.167.3920.1005 
Deehan Jr., G. A., Brodie, M. S., \& Rodd, Z. A. (2013). What Is in That Drink: The Biological Actions of Ethanol, Acetaldehyde, and Salsolinol. Current Topics in Behavioral Neurosciences, 13, 163-184.

Deehan Jr., G. A., Hauser, S. R., Wilden, J. A., Truitt, W. A., \& Rodd, Z. A. (2013). Elucidating the Biological Basis for the Reinforcing Actions of Alcohol in the Mesolimbic Dopamine System: The Role of Active Metabolites of Alcohol. Frontiers in Behavioral Neuroscience, 7, 104.

Dulcis, D., Jamshidi, P., Leutgeb, S., \& Spitzer, N. C. (2013). Neurotransmitter Switching in the Adult Brain Regulates Behavior. Science, 340, 449-453. http://dx.doi.org/10.1126/science.1234152

Ebadi, M. S., Weiss, B., \& Costa, E. (1970). Adenosine 3'-5'-Monophosphate in Rat Pineal Gland: Increase Induced by Light. Science, 170, 188-190. http://dx.doi.org/10.1126/science.170.3954.188

El Halawani, M. E., Kang, S. W., Leclerc, B., Kosonsiriluk, S., \& Chaiseha, Y. (2009). Dopamine-Melatonin Neurons in the Avian Hypothalamus and Their Role as Photoperiodic Clocks. General and Comparative Endocrinology, 163, 123-127. http://dx.doi.org/10.1016/j.ygcen.2008.11.030

Ericson, M., Molander, A., Lof, E., Engel, J. A., \& Soderpalm, B. (2003). Ethanol Elevates Accumbal Dopamine Levels via Indirect Activation of Ventral Tegmental Nicotinic Acetylcholine Receptors. European Journal of Pharmacology, 467, 85-93. http://dx.doi.org/10.1016/S0014-2999(03)01564-4

Geller, I. (1971). Ethanol Preference in the Rat as a Function of Photoperiod. Science, 173, 456-459. http://dx.doi.org/10.1126/science.173.3995.456

Geller, I., \& Blum, K. (1970). The Effects of 5-HTP on Para-Chlorophenylalanine (p-CPA) Attenuation of “Conflict” Behavior. European Journal of Pharmacology, 9, 319-324. http://dx.doi.org/10.1016/0014-2999(70)90229-3

Hamilton, M. G., Blum, K., \& Hirst, M. (1978). Identification of an Isoquinoline Alkaloid after Chronic Exposure to Ethanol. Alcoholism, Clinical and Experimental Research, 2, 133-137. http://dx.doi.org/10.1111/j.1530-0277.1978.tb04713.x

Hamilton, M. G., Blum, K., \& Hirst, M. (1980). In Vivo Formation of Isoquinoline Alkaloids: Effect of Time and Route of Administration of Ethanol. Advances in Experimental Medicine and Biology, 126, 73-86. http://dx.doi.org/10.1007/978-1-4684-3632-7_8

Hamilton, M. G., Hirst, M., \& Blum, K. (1979). Opiate-Like Activity of Salsolinol on the Electrically Stimulated Guinea Pig Ileum. Life Sciences, 25, 2205-2210. http://dx.doi.org/10.1016/0024-3205(79)90093-6

Hendrickson, L. M., Zhao-Shea, R., \& Tapper, A. R. (2009). Modulation of Ethanol Drinking-in-the-Dark by Mecamylamine and Nicotinic Acetylcholine Receptor Agonists in C57BL/6J Mice. Psychopharmacology, 204, 563-572.

http://dx.doi.org/10.1007/s00213-009-1488-5

Hipolito, L., Sanchez-Catalan, M. J., Granero, L., \& Polache, A. (2009). Local Salsolinol Modulates Dopamine Extracellular Levels from Rat Nucleus Accumbens: Shell/Core Differences. Neurochemistry International, 55, 187-192. http://dx.doi.org/10.1016/j.neuint.2009.02.014

Marshall, A., Hirst, M., \& Blum, K. (1977). Analgesic EFFECTS of 3-Carboxysalsolinol Alone and in Combination with Morphine. Experientia, 33, 754-755.

Matsuzawa, S., Suzuki, T., \& Misawa, M. (2000). Involvement of Mu-Opioid Receptor in the Salsololin-Associated Place Preference in Rats Exposed to Conditioned Fear Stress. Alcoholism, Clinical and Experimental Research, 24, 366-372.

Melchior, C. L., Simpson, C. W., \& Myers, R. D. (1978). Dopamine Release within Forebrain Sites Perfused with Tetrahydroisoquinolines or Tryptoline in the Rat. Brain Research Bulletin, 3, 631-634. http://dx.doi.org/10.1016/0361-9230(78)90009-6

Melis, M., Carboni, E., Caboni, P., \& Acquas, E. (2013). Key Role of Salsolinol in Ethanol Actions on Dopamine Neuronal Activity of the Posterior Ventral Tegmental Area. Addiction Biology. http://dx.doi.org/10.1111/adb.12097

Miguel Asai, M. A., Lilian Mayagoitia, L. M., David Garcia, D. G., Gilberto Matamoros-Trejo, G. M., Marcela Valdes-Tovar, M. V., \& Phillipe Leff, P. L. (2007). Rat Brain Opioid Peptides-Circadian Rhythm Is under Control of Melatonin. Neuropeptides, 41, 389-397. http://dx.doi.org/10.1016/j.npep.2007.09.001

Myers, R. D. (1989). Isoquinolines, Beta-Carbolines and Alcohol Drinking: Involvement of Opioid and Dopaminergic Mechanisms. Experientia, 45, 436-443. http://dx.doi.org/10.1007/BF01952025

Myers, R. D., \& Veale, W. L. (1968). Alcohol Preference in the Rat: Reduction Following Depletion of Brain Serotonin. Science, 160, 1469-1471. http://dx.doi.org/10.1126/science.160.3835.1469

Namboodiri, M. A., Sugden, D., Klein, D. C., Tamarkin, L., \& Mefford, I. N. (1985). Serum Melatonin and Pineal Indoleamine Metabolism in a Species with a Small Day/Night N-Acetyltransferase Rhythm. Comparative Biochemistry and Physiology. B, Comparative Biochemistry, 80, 731-736. http://dx.doi.org/10.1016/0305-0491(85)90453-5

Peres, R., do Amaral, F. G., Madrigrano, T. C., Scialfa, J. H., Bordin, S., Afeche, S. C., \& Cipolla-Neto, J. (2011). Ethanol Consumption and Pineal Melatonin Daily Profile in Rats. Addiction Biology, 16, 580-590.

http://dx.doi.org/10.1111/j.1369-1600.2011.00342.x 
Raiewski, E. E., Elliott, J. A., Evans, J. A., Glickman, G. L., \& Gorman, M. R. (2012). Twice Daily Melatonin Peaks in Siberian but Not Syrian Hamsters under 24 h Light:Dark:Light:Dark Cycles. Chronobiology International, 29, 1206-1215. http://dx.doi.org/10.3109/07420528.2012.719965

Reiter, R. J., Blum, K., Wallace, J. E., \& Merritt, J. H. (1973). Effect of the Pineal Gland on Alcohol Consumption by Congenitally Blind Male Rats. Quarterly Journal of Studies on Alcohol, 34, 937-939.

Reiter, R. J., Blum, K., Wallace, J. E., \& Merritt, J. H. (1974). Pineal Gland Evidence for an Influence on Ethanol Preference in Male Syrian Hamsters. Comparative Biochemistry and Physiology A: Comparative Physiology, 47, 11-16. http://dx.doi.org/10.1016/0300-9629(74)90045-0

Robichaud, R. C., \& Sledge, K. L. (1969). The Effects of P-Chlorophenylalanine on Experimentally Induced Conflict in the Rat. Life Sciences, 8, 965-969. http://dx.doi.org/10.1016/0024-3205(69)90427-5

Rodd, Z. A., Oster, S. M., Ding, Z. M., Toalston, J. E., Deehan, G., Bell, R. L., Li, T. K., \& McBride, W. J. (2008). The Reinforcing Properties of Salsolinol in the Ventral Tegmental Area: Evidence for Regional Heterogeneity and the Involvement of Serotonin and Dopamine. Alcoholism, Clinical and Experimental Research, 32, 230-239. http://dx.doi.org/10.1111/j.1530-0277.2007.00572.x

Sallstrom Baum, S., Hill, R., Kiianmaa, K., \& Rommelspacher, H. (1999). Effect of Ethanol on (R)- and (S)-Salsolinol, Salsoline, and THP in the Nucleus Accumbens of AA and ANA Rats. Alcohol, 18, 165-169. http://dx.doi.org/10.1016/S0741-8329(98)00080-9

Self, D. W., \& Nestler, E. J. (1998). Relapse to Drug-Seeking: Neural and Molecular Mechanisms. Drug and Alcohol Dependence, 51, 49-60. http://dx.doi.org/10.1016/S0376-8716(98)00065-9

Sinclair, J. D. (1972). The Alcohol-Deprivation Effect. Influence of Various Factors. Quarterly Journal of Studies on Alcohol, 33, 769-782.

Sleipness, E. P., Jansen, H. T., Schenk, J. O., \& Sorg, B. A. (2008). Time-of-Day Differences in Dopamine Clearance in the Rat Medial Prefrontal Cortex and Nucleus Accumbens. Synapse, 62, 877-885. http://dx.doi.org/10.1002/syn.20552

Steiner, S. A. (1958). Meprobamate for Alcohol Addiction; a Psychotherapeutic Adjunct. The Medical Annals of the District of Columbia, 27, 350-351.

Wang, F., Simen, A., Arias, A., Lu, Q. W., \& Zhang, H. (2013). A Large-Scale Meta-Analysis of the Association between the $A N K K_{1} / D R D_{2}$ Taq $_{1}$ A Polymorphism and Alcohol Dependence. Human Genetics, 132, 347-358. http://dx.doi.org/10.1007/s00439-012-1251-6

Yaegashi, T., Jin, J., Sawada, T., Saito, H., Fulop, F., Nagy, G. M., \& Hashizume, T. (2012). Effects of Photoperiod on SalsolinolInduced Prolactin Secretion in Goats. Animal Science Journal, 83, 418-425.

http://dx.doi.org/10.1111/j.1740-0929.2011.00965.x 